\title{
A Step Towards Revolution In Logistics And Cold Chain Management In India- A Case Study On Public Undertaking "Fresh And Healthy Enterprise Limited-CONCOR, Ministry Of Railways-, Govt. Of India
}

\author{
Navita Mahajan \\ Assistant Professor Amity International Business School,Amity University Noida, Uttar Pradesh,India
}

\begin{abstract}
With the advent of globalization and internationalization of products, the preference is always for the best quality and if not matched then product is out of the competition. Apple being premium product in fruit category would demand very high standards as far as product presentation and variety is concerned, since world wide best quality product is available leading the trade. Fresh and Healthy Enterprise Limited, Subsidiary of Concor India, Ministry of Railways-Government of India, has made a remarkable and unique presence in Logistics and storage technology however on the backend, the fruit quality, quantity, variety and market conditions could limit the progress in a time to come. We are aware of the challenges and solutions therefore as well, so it's the high time that we need to control the links of supply chain and re-map it for the future generations of India and Indian economy on the global platform.
\end{abstract}

Key Words: Concor India, Fresh and Healthy Enterprise Limited(FHEL), CA(Controlled Atmosphere), APMC(Agricultural Produce Marketing Committee), Logistics

\section{Introduction}

Integrated cold Supply Chain is recognized as a sunrise sector in India. It is need of the hour for a country like ours that ranks first in fruit production in the world with its annual production of 146 million MT fruits however post harvest wastage up to $30-40 \%$, hence demanding a very robust mechanism to be the world leader in post harvest technology and marketing infrastructure.

Globalization has made the world smaller in many respects and lot of preferences is there for international products. However transportation of Perishables across locations is a challenging factor which depends on the actual distance between two locations and the risk associated with the logistics like perishability risk, damage risk etc. exist due to factors like temperature variations, shock during transfer and humidity factors etc.

The use of latest technology of controlled atmosphere (CA) storage has become a staple of the fruit industry now days. It is one of the tools that allow growers and packers to extend the available seasons for produce and meet demand with supply. CA storage is a system where fresh, perishable fruits and vegetables are stored under narrowly defined environmental conditions that extend the useful marketing period after harvest.

Maintenance of cold supply chain of Fruit and Vegetables is of the major thrust area declared by Govt. of India and many state of art cold storages have emerged over a period of time in Public and private sector both for perishables.

The time when we talk about FDI in retail, globalization, public-private partnership of infrastructure, benchmarking our post harvest management practices with international standards, a major breakthrough has already been made by a Public sector entity - FHEL(M/S Fresh and Healthy Enterprise Limited), which a subsidiary of CONCOR India - a pioneer in efficient and reliable multi-modal logistics support for the country's exim and domestic trade and commerce under Ministry of Railways, Govt. of India.

Incorporated on $1^{\mathrm{ST}}$ February,2006, the major objective of the company was to apply new scientific methods to all aspects of post-harvest management including proper handling of produce starting from the farm, during cold storage, transport in refrigerated containers and distribution, to bring freshness and value to the food supply chain. To facilitate this company installed State of the art Controlled Atmosphere Facility commissioned in August 07, at Rai, Kundli Haryana, wherein they have re-engineered the Apple supply chain of India. 

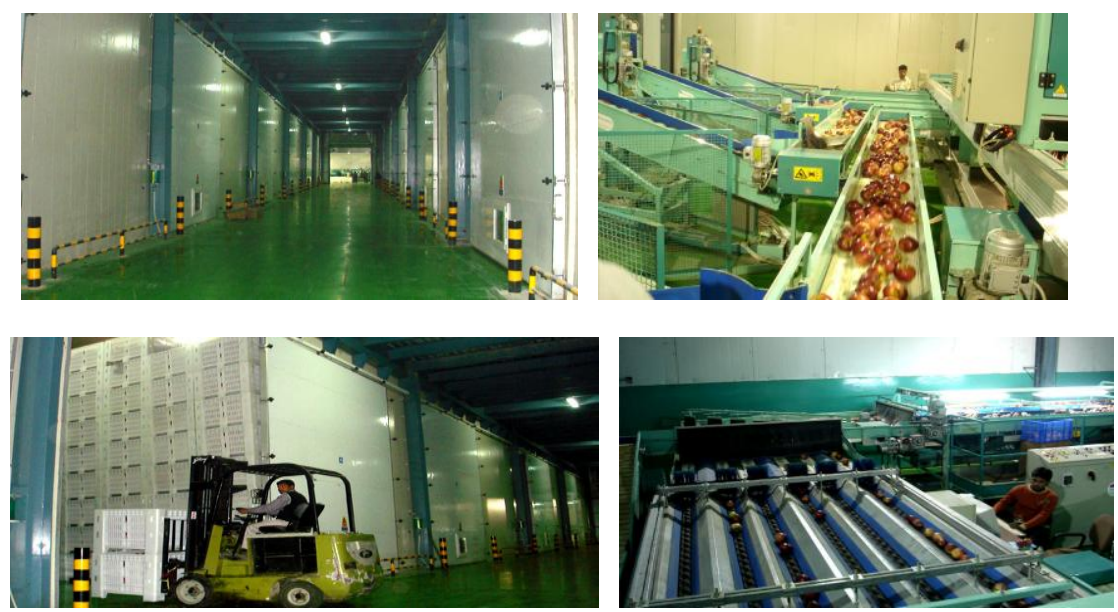

FHEL Facility at Rai

\section{Why FHEL Was Set Up?}

FHEL is a wholly owned subsidiary of CONCOR India which is one of the most accomplished Multi Modal Logistics Company with 58 container depots all over the country. CONCOR has lion share of the containerized rail business in the country and also has container terminals in ports and airports. For such a prime and a Mini-Navratna Logistic company in India, the wastage of 30-40\% in fresh produce due to inadequate cold chain and logistics was a great challenge. Since the parent company was already well established in Logistics, FHEL was set up to take care of the needs of Fruit and Vegetable sector leveraging the in-house expertise, technology and infrastructure of the parent company.

\section{FHEL Goes Strategic For Location And Product Selection}

FHEL'S approach was highly strategic while selecting location to install facility as well as product to be stored on volume basis for the best capacity utilization of the facility. The location of the place was chosen in view of readily available market, so a location near Delhi was the most conducive place for FHEL as Agricultural Produce Market Committee, Azadpur, which is Asia's largest Mandi for trading of fruits is situated here and is having highest volumes in transit as well as termination of products. The mandi has highest trade volumes of Apples and throughout the year APMC Azadpur supplies tonnes of Apples to distant markets all over the country on regular basis. The facility was installed in HSIDC Park, Rai, Kundli Haryana which is around $25 \mathrm{Km}$ from APMC Azadpur.

Apples in India are primarily grown in two states i.e. Jammu \& Kashmir and Himachal Pradesh. The apples from Kinnour district of Himachal Pradesh have unique flavour, excellent quality and long storage life. Taking cognizance of this FHEL selected Himachal Pradesh for its operations with enhanced focus on procurement from Kinnaur district. The selection of product for storage i.e. apple has also been done after careful consideration. Apple has demand throughout the year and also has very good storage life in Controlled Atmosphere (CA) conditions i.e. 7 - 8 months. FHEL has been pioneer in bringing CA technology to India. FHEL set up its CA Store in 2007 , at that point in time there was no other store in the country using CA technology. Initially there was lot of skepticism w.r.t. the viability. But with consistent efforts and self-belief the company has been able to prove itself. After seeing success of FHEL number of private players has also ventured in to this field. Some of them have been associated with FHEL while others have got motivated by its success. As a result the country has benefited on many fronts. Due to competition, the farmers are getting good value for their produce, consumer is getting good quality apples from CA and imports are not increasing at same pace as they would have if the CA stored had not been set up in the country thereby saving precious foreign exchange.

Apple production in India is approx. 20 Lacs MT, whereas cold storage facility available is only 1 Lac MT and also CA storage technology which is the most recommended for this product is only 35,000MT.So there is huge shortfall in the CA capacity being installed in the country,

The business strategy of FHEL is to focus on where state has got the unique advantage, the production belt is far from consumption, produce is seasonal in nature and the consumption is throughout the year in all over the regions of the country. The product due its price sensitivity targets medium to premium class during the off season, festivals while up to some extent masses during the season in medium to low quality. Apples can be stored as long as seven months in a well furnished Controlled Atmosphere storage. The technology gave an 
upper periphery to FHEL over the ordinary cold stores in North India where traders traditionally store Apples only for 4-5 months, also quality and shrinkage losses are higher, whereas in CA the product is crisp and juicy even after 6-7 months with minimal shrinkage and rotting.

\section{USP of FHEL Controlled Atmospheric Facility \& Integrated Cold Chain}

FHEL offers some of the unique features in its facility like,

$>\quad$ Biggest of its kind in the country (12,000 MT).

$>\quad 78$ chambers which can be operated from centralized control and independently

$>\quad$ Latest computer control of

- Temperature

- Oxygen

- Nitrogen

- Carbon Dioxide

- Humidity

Grading and sorting lines imported from Sammo, Italy.

$>$ Automatic washing and waxing facility.

$>$ Both bulk and retail packing machines from Italy.

$>$ Refrigeration and air conditioning equipments are from Germany, China etc.

$>$ For storage of fruits and vegetables we have plastic bins made of food grade plastic from Israel.

$>200 \%$ power backup.

$>$ Entire facility is A.C. including grading and packing area.

$>$ All movements inside the facility are by battery operated forklifts and electric stackers.

$>$ End to End Cold chain solution from Farm Gate to wholesaler/distributor to retailers/chain/fruit marts.

$>$ Strong Logistics Focus

$>$ National wide presence

III. Journey Of Success Of FHEL Since August 2006...

Starting up operations in 2006, FHEL started with only 1200 MT of Apples in CA storage . That was the first year of operations where company tried to do lot of experiments with logistics and bringing the product from far flung areas of Himachal Pradesh and filling chambers was not an easy task. Many problems like availability of material, farmers' agreements, trucks, capacity utilization of trucks, labour, transshipment, quality losses, filling of chambers, marketing the produce at right time in the right market were some of the key issues. Whereas FHEL was strong in technology and logistics , but marketing was a new area for them. The company tied up with local wholesalers of Azadpur Mandi but the reach of product in market was not up to the expectations of FHEL.

FHEL with its strong technology and a financial strength of parent company had the aspirations to distribute its product all the country at the best prices with no malpractices which is otherwise was very much prevalent in the trade. In an attempt to fulfill its goals, Company tie up with a Chile bases Multinational Company operating in India which had a strong base in marketing Apple, not only in India but all over the world. It was major milestone and win-win situation for FHEL, apart it continued the relations with local traders as well.

Through the Multinational, FHEL not only got all India Presence but a strong backup for its Produce as well. The efforts did not end here, the company tried all the best other possible ways to position their product in other formats of market like retail sector and cash parties of distant locations.

In the second year of operation, the volumes of FHEL in procurement grown up to 11,000 MT, out of which 10,000 was in CA and 1,000 MT in cold store. The Apples were sold by an Indian company from a CA Store for the first time till June, however still some quality problems were reported, nevertheless gaps were identifies and technology solutions were found.

Year three of operations, 2008-09 was the time for FHEL, when they achieved high quality in produce, also started with washing and waxing of Apples that fetched prices close to imported Apples. The company could sell large quality of Apple in Mumbai and Northern Indian Market. Time to time company introduced new styles in packaging like premium 2 layer boxes in $10 \mathrm{Kg}$ category, tray packs, which proved to be fast moving items and very popular among semi-wholesalers, retailers as well as consumers for gift purpose.

FHEL by its experience, product, technology and expertise of Cross functional teams, is now a leader in Himachal Apples in India. Company is not only leading in Logistics and cold chain but Farm Extension services to provide guidance to grower on correct Agriculture practices to ensure better quality fruits and better yields. Farmers are also being trained on Maturity testing of fruits and harvesting at proper time with on farm consolidation techniques in order to avoid any quality losses. The company has not a well established protocol for Apples like

- Plucking at right maturity time

- Transportation by reefer from farm to store and from store to markets.

- Grading, sorting, washing, waxing on mechanized lines under controlled conditions. 
- $\quad$ Maintenance of prescribed temperature and Relative Humidity.

\section{Future Challenges}

Having established a well designed integrated cold supply chain Management in Apple, still lot many challenges are there on the way which company would have to contest time to time in order to maintain its position .

1.The orchards in Himachal Pradesh are 25-30 years old and varietal constrains are there especially in the lower belts of the Apple growing regions. The premium varieties are available in few selected pockets only in upper regions, so rejuvenation of orchards and quality produce availability is going to be a main challenge of FHEL.

2. The premium varieties available in Himachal Pradesh, especially Royal Delicious variety from Kinnour area demand premium procurement prices, due to limited quantities. Adding on CA storage and other charges, the produce has a tough competition with Imported varieties from USA and China when December onwards the shipments start arriving in India. Sometimes the imported product is available at a cheaper price that domestic, so price factors are very sensitive.

3. Running the facility of 12000 MT capacity on full utilization is again a challenging factor, as Apple crop is severely affected by any disruption in weather conditions of the area and plant requires minimum number of chilling hours. So far FHEL storage facility is dependent mainly on Apples, so although FHEL rents out facility to other parties during off season, but it should also have a strong backup plan, if Apple crop is not good in Himachal Pradesh. Although company has done trials in Kinnow, Mangoes, Oranges, Grapes but a concrete business plan ill have to be defined.

4. In India, over $90 \%$ fruit is sold through open market system like Push Cart Vendors, Roadside vendors, nonpermanent shops, which do not have any cold chain facility to maintain the products temperature. So the product which is kept for 6-7/8 months in CA gets severe heat injuries and deterioration in quality due to temperature outside especially during April-May. It's a serious threat to fruit quality as well as market value of the produce.

5. Apart from paying the declared procurement price to farmers, company will have to engage itself in other Corporate Social Responsibility in the selected areas, in order to have long term association with the farmers.

6. The Labour union system prevailing in the facility, wherein grading-sorting and loading labour is arranged through a designated vendor is a challenge due to constantly emerging conflicts, which affect ultimately operations only.

7. FHEL is Undoubltly handing the product in a highly sophisticated manner, but the way it is further handled in Mandis after being sold by the company is another area of concern. Apart from that since the traditional way of mandi trading works on 30-40 days credit system, the rules of the games are changed for FHEL, financial risks can not be taken being a public sector company.

\section{Conclusion:}

If people in India are willing to buy 1.35 lac MT of apples from abroad, then it means that they are surely looking for improved quality of the local apples. The industry is expected to see a major change in business in coming 3-4 years, where logistics and cold chain management are going to play an important role .Gains in the business can not be achieved until all the links of chain are controlled and managed. With the nutrition recommendation of five daily servings of fruits and vegetables gaining an increasing number of followers in urban Indian households, the outlook is bright for fresh fruit and vegetable sales, so here is the window of opportunity for FHEL and other players in Integrated Chain Management field to bring a revolution in Indian Integrated Cold Chain Management sector.

\section{References}

[1] Patnaik, Gokul. 2011, Status of Agricultural Marketing Reforms. Paper presented at workshop on Policy Options and Investment Priorities for Accelerating Agricultural Productivity and Development in India, New Delhi, India, November, 10-11, 2011. http://www.igidr.ac.in/newspdf/srijit/PP-069-11b.pdf (accessed January 26, 2012).

[2] Pandey, Mukesh, Gregory A. Baker and Deepali Tewari Pandey, Supply Chain Re-engineering in the Fresh Produce Industry, A Case Study of Adani Agrifresh,2013

[3] Jawa,N.K, Adding Value through cold chain, presentation, Fresh and Healthy Enterprise Limited, 2012. 